\section{Nobel Metal Microscopes - and Other Extravagances} John Gustav Delly, McCrone Research Institute

Now you would probably think that I was joking if I were to tell you that there are microscopes made of precious metals, such as silver, rather than brass, and objectives made with diamonds and rubies, rather than glass. But yes, Virginia, prodigal items such as these do actually exist - and not at the end of the rainbow. All right, suppose they do exist, who could afford one? Well, kings for one. Figure 1 shows what is perhaps the most elaborately decorated microscope ever constructed. It was made in 1761 by the wellknown instrument maker George Adams for King George III. George III placed great value on science throughout his long reign, as reflected in his collection of scientific instruments, which can be seen today in the Science Museum at South Kensington in London. No microscopist worth his planapos can be in London without spending at least a day with the microscopes in this collection. There are many microscopes in the George III collection, but the one illustrated here really takes the prize. It is actually made of brass and steel encased with beaten silver, and is a sterling (pardon the expression) example of artistic silversmithing. In the center is a Corinthian pillar on a pedestal. Short pedestals on either side bear ornamental urns. There are cherubim figures and foliage at the base of the pedestal, and decorated silver tubing joins the two side pedestals. Note the two partially draped female figures supporting the microscope bodytube.

Unfortunately, it is not a very easy instrument to use. It stands $736 \mathrm{~mm}$ high, which is far too tall for use on a table and it cannot be inclined. Especially interesting features of this microscope include the two stages - a matched pair - each with its own mirror. Actually, there are two microscopes here: the main tube supported by the figures houses a compound microscope, and a simple microscope is mounted in back, over the second stage. There are eight magnifications carried on a large wheel which rotates just

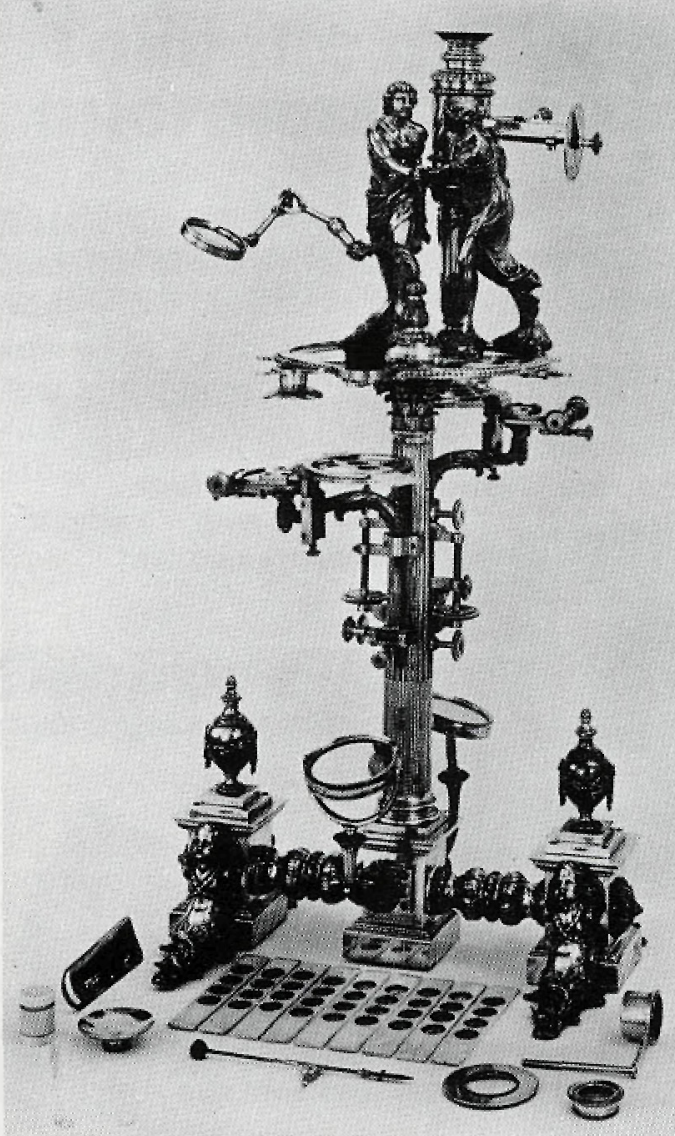

Figure 1 below the platform. Complete optical and mechanical descriptions of this silver microscope are recorded by Clay and Court in their The History of the Microscope, (Charles Griffin Company, London, 1932). A brief description also appears in Microscopes to the End of the 19th Century by Palmer and Sahiar, a Science Museum illustrated booklet (1971).

Clay and Court also mention in their book still another microscope made of silver - all silver. It is a pocket microscope invented and made in 1728 by George Lindsay, a London watchmaker. It also happens to be the first microscope which was ever patented (1743). The microscope itself consists of a flat, Y-shaped base with a slender, rising pillar, on top of which is mounted an inclined foundation plate. The top of the plate holds a fixed objective - one of two in interchangeable sliders. The stage, which lies below the objective is fitted into grooves. Focusing is accomplished by moving the stage to and fro in these grooves. The mirror is mounted on an extension of the foundation plate. This is reported to be the first time that a mirror was attached to the limb of a simple microscope. A low-power Lieberkuhn type objective is also provided. The entire microscope does not stand much higher than about $15 \mathrm{~cm}$ when fully extended for use. When not being used, the microscope folds into a very small case which somehow also manages to house some sliders, covers and instruments. In solid silver this pocket microscope makes an especially pretty package.

Jewels were used to make objective lenses, but not just for the sake of luxury. Brewster pointed out the advantages of precious stones over glass in 1811-13. Such lenses would be superior to glass owing to higher refractive index and lower dispersion. The higher refractive index permitted less radius of curvature than glass for a given power, and therefore less spherical aberration (1/9th that of glass), the lower dispersion resulted in less chromatic aberration.

In 1824, Dr. Goring persuaded Pritchard to try to make a diamond lens. Pritchard succeeded, and afterwards made two piano-convex diamond lenses of $1 / 20 "$ and $1 / 30 "$ focal length. Objective lenses were made out of diamond, ruby, sapphire, garnet and topaz. The idea was basically sound, but there were many problems, quite apart from the expense and difficulty of grinding and polishing the jewels; namely, flaws in the material, and the fact that if the stones belonged to any but the cubic crystal system they would be doubly refracting and result in multiple images. To overcome this, the lens had to be made with the gem oriented in such a way that one was looking down the isotropic axis. Even diamonds suffered in spite of the fact that they are in the cubic system, because it seems they can crystallize in layers of slightly different refractive index, resulting in multiple images again. Other problems with diamond included unequal hardness in different directions. Still, several diamond lenses were successfully made. One completed diamond lens in the Museum at Utrecht was tested and found to have a magnifying power of $990 \mathrm{X}$. These experiments did not last long, because about this same time there were rapid improvements being made in the development of glass achromatic lenses. Further details on

Continued on page 18

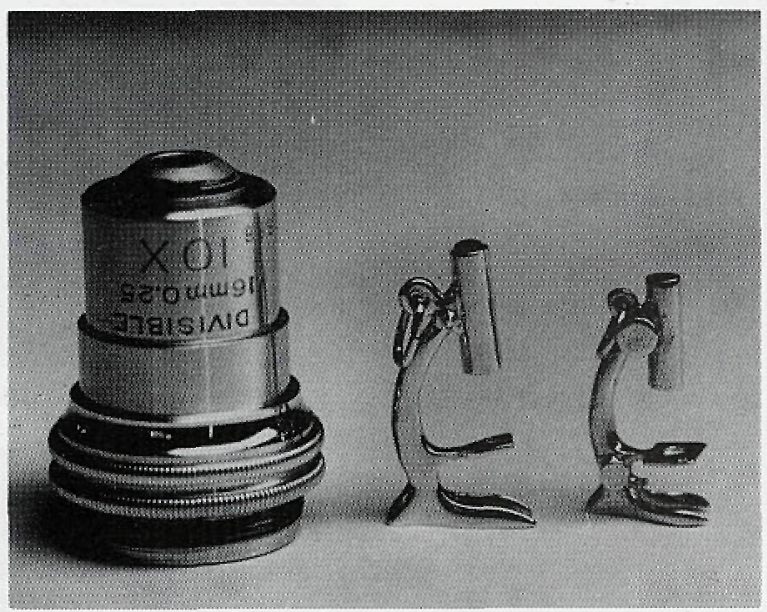

Figure 2 


\section{Digital Productivity vs Darkroom Drudgery}

Advantage Series TEM Camera Systems

- 1024 or 2048 Pixel Resolution

- Lens or Fiber Optic Coupling

- Large Field of View

- PC Based Turnkey Systems

- Standard TIFF File Format

- Axial or Side Mount Systems

Up to 4096 Gray Levels

- Fast Acquisition Speeds

Advanced Microscopy Techniques Corporation

3 Electronics Avenue Danvers, MA 01923

Tel: (978)774-5550 Fax: (978)739-4313

Email: amtcorp@delphi.com

WWW: http://www.msa.microscopy.com/ amt/ 


\section{WHERE KNOWLEDGE MAKES THE DIFFERENCE}

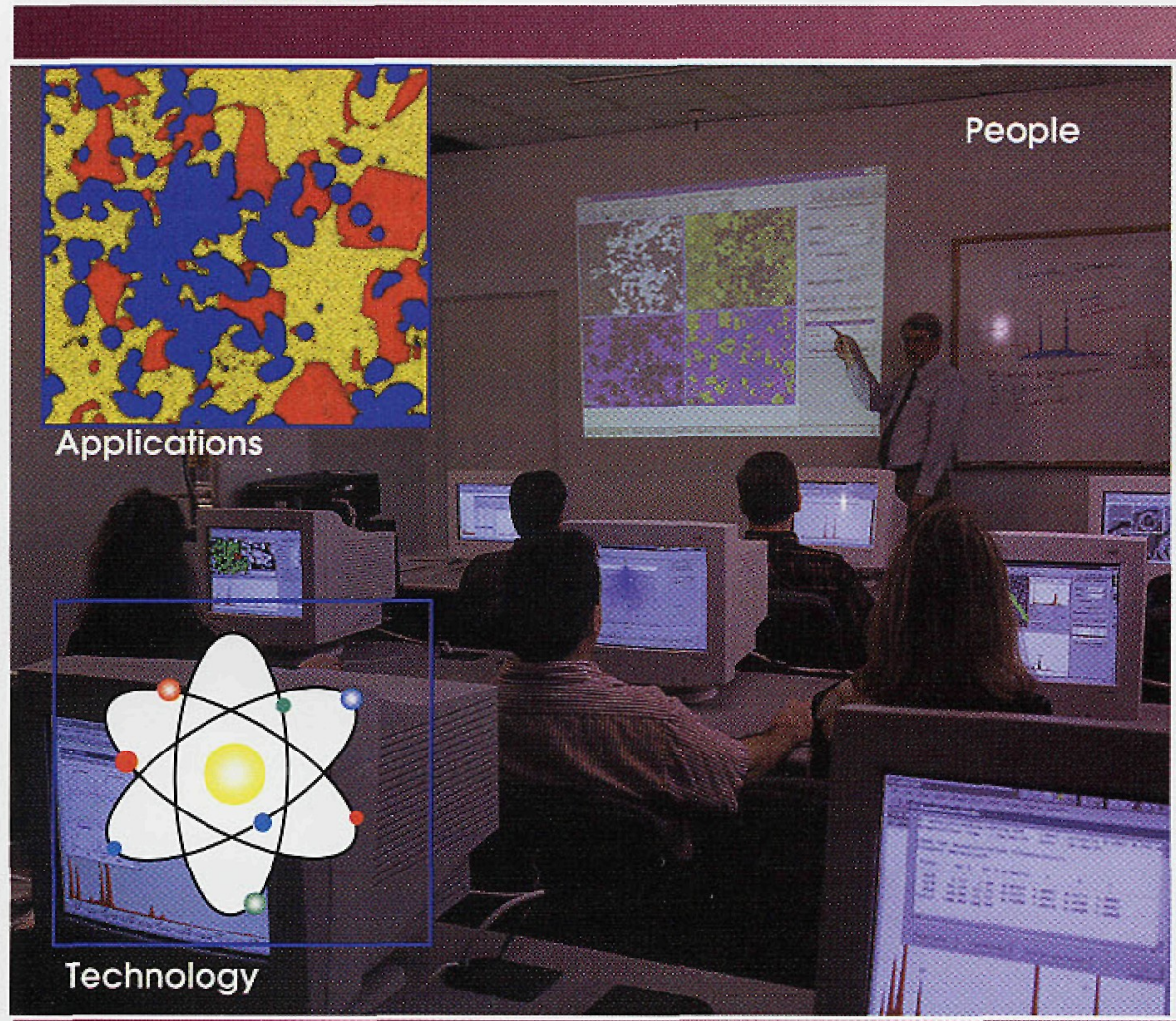

EDAX OFFERS SUPERIOR

PRODUCTS, TRAINING

\& SUPPORT.....

$\Delta$ Highly skilled professional staff

$\Delta$ Wide range of high performance detecting units

$\Delta$ Diverse number of integrated system offerings

$\Delta$ Comprehensive range of upgrade paths

$\triangle$ EDAX is ISO 9001 certified

$\Delta$ An overall commitment to excellence

\section{Nobel Metal Microscopes ...}

Continued from page 16

these jeweled lenses and references to additional sources can be found in the book by Clay and Court mentioned earlier, and in Bradbury's The Evolution of the Microscope (Pergamon Press, 1967).

George III's silver microscope was made more than 200 years ago, and the jeweled lenses were made over 125 years ago. What of today? Nobody today is making either silver microscopes or jeweled lenses, but in the last 15 years I have managed to acquire two microscopes with the Midas touch, so to speak. Yes, I mean 14 Karat solid-gold microscopes. Admittedly they are a bit smaller than your common garden variety microscope - I show them in Figure 2 next to an ordinary microscope objective for size reference! The microscope on the left, next to the 10X objective, contains a Stanhope lens, the top of which is just visible above the bodytube. The Stanhope lens is a glass cylinder with a convex surface on one end and a plane surface on the other. In practice, a microphotograph is mounted on the plane end and covered with a tiny coverslip. For details of the Stanhope lens and microphotographs, see G.W.W. Stevens' Microphotography, Wiley, 1968. There is a microphotograph mounted in the Stanhope lens of the microscope on the left, which can be seen if the instrument is held close to the eye while looking toward a source of light. This particular microphotograph is a heart, inscribed "I love you" - so what did you expect from a $14 \mathrm{~K}$ gold microscope, a transverse section of Amphioxus in Mallory's triple stain?

Speculating on the possibility of commissioning Cartier to make a platinum-iridium microscope with gilt drawtube and Wedgewood accessories is good for a quarter hour's escapism.

$A h$, for the days of gilt and glass.... of silver and topaz.... when one could say, "let me tell you about this gem of a microscope I just picked up" and mean it.

\section{A Tell-Tale Heartwood \\ Eric C. Kellar, University of Pittsburgh Kellarec@msx.upmc.edu}

In Medieval Europe, manuscripts and formulas on the preparation of colors and dyes used by chemists and artists contained many references to natural plant extracts. The yellow stigmas of aromatic saffron (Crocus sativus) were crushed and used both as a medicine and colorant as far back as the ninth

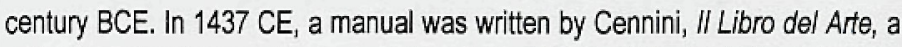
collection of recipes on the preparation of tempera and block-printing inks from saffron and brazilwood (Caesalpinia echinata). Finely divided brazil wood was prepared by scraping sticks with a knife. One could then:

Place it directly in 'glair' paint medium (egg white) with alum - or boil it in red wine and urine and alum, dry and then grind. Boil with 'lye' (alkaline wood ash), then mordant onto an inert base by adding marble dust and alum in quantities equal to that of the brazil. They seem to disagree on the necessity of an alkaline bath (urine or lye), but agree on alum as necessary to prevent colour loss. (Translation from Cennini text 1437 CE.)

The pods of several South American species of Caesalpinia, including $C$. brevifolia (algarobilla), C. coriaria (divi-divi) and C. spinosa (tara) yield an important source of natural tannins. The tannins react with collagen protein in animal skin, converting the skin into leather. The heartwood from a thorny South American tree called brazilwood contains a red dye used for cotton, wool and preparing inks. During the Middle Ages, the main commercial source of this dye came from an Indian species (C. sappan), called "bresil" or "brasil" by Portuguese traders, referring to the bright red heartwood. Early in the sixteenth century, the Portuguese discovered the South American species and transferred the Old World name to it, eventually becoming known as brazilwood. In 